\title{
The Occurrence of Pesticides and Polycyclic Aromatic Hydrocarbons in Residential Dust in North Carolina
}

\author{
Rebecca Anthopolos ${ }^{1}$, Martha Keating ${ }^{2}$, David Camann ${ }^{3}$, and Marie Lynn Miranda ${ }^{1,4 *}$ \\ ${ }^{1}$ School of Natural Resources and Environment, University of Michigan, USA \\ ${ }^{2}$ Keating Environmental, Efland, NC 27243, USA \\ ${ }^{3}$ Department of Analytical and Environmental Chemistry, Southwest Research Institute, San Antonio, Texas, 78228-0510, USA \\ ${ }^{4}$ Department of Pediatrics, University of Michigan, USA
}

\begin{abstract}
The objective of this study was to characterize the occurrence and concentration of pesticides and polycyclic aromatic hydrocarbons (PAH) in household dust in North Carolina. Human exposure to these contaminants in the indoor environment is of concern since little degradation takes place indoors resulting in chronic exposure to a mixture of contaminants. In addition, children may be more highly exposed due to hand-to-mouth activities and increasing time spent indoors. We recruited 199 households in Central and Eastern North Carolina and collected composite dust samples over two April-October sampling seasons during 2003 and 2004. Dust samples were analyzed for 16 pesticides ( $\alpha$-chlordane, $y$-chlordane, 2,4-D(2-ethylhexyl) ester, alachlor, carbaryl, chlorpyrifos, cis- and transpermethrin, 4,4'-DDE, 4,4'-DDT, dieldrin, diazinon, heptachlor, lindane, methoxychlor, and ortho-phenylphenol) andfour PAH compounds (benzo(b)fluoranthene, chrysene/iso-chrysene, benzo(a)pyrene, and benz(a)anthracene). The frequency of detection varied for the pesticides; the median number of pesticides detected in sampled homes was seven. The four PAH were found in more than $97 \%$ of sampled homes. Detection frequency and concentration of insecticides banned for residential uses were significantly associated with whether the residence was built before or after the ban year $(\mathrm{P}<0.001$ in all cases except for dieldrin where $\mathrm{P}<0.01$, and methoxychlor). Under maximum exposure scenarios, somewhat elevated health risk estimates were calculated, with the majority of the risk attributable to exposure to the banned insecticides dieldrin and DDT. This study provides additional regional data about the mixture and level of contaminants in household dust in the southeastern U.S.
\end{abstract}

\section{Keywords: Dust; PAH; Pesticides; Risk assessment}

Abbreviations: EPA: U.S. Environmental Protection Agency; HI: Hazard index; HQ: Hazard quotient; PAH: Polycyclic aromatic hydrocarbons; RfD: Reference dose; ROS: Regression on Ordered Statistics; SwRI: Southwest Research Institute

\section{Introduction}

Exposure to chemical contaminants in the indoor environment is a growing concern as individuals, especially children, spends increasing amounts of time indoors. Residential dust provides an objective measure of specific compounds in the indoor environment and can indicate the magnitude of potential human exposure. This paper describes the results of composite dust analyses from 199 households in Central and Eastern North Carolina. Dust samples were analyzed for 16 pesticides ( $\alpha$-chlordane, $\gamma$-chlordane, 2,4-D (2-ethylhexyl) ester, alachlor, carbaryl, chlorpyrifos, cis- and trans-permethrin, 4,4'-DDE, 4,4'-DDT, dieldrin, diazinon, heptachlor, lindane, methoxychlor, and ortho-phenylphenol) and four PAH (benzo(b)fluoranthene, chrysene/ iso-chrysene, benzo (a) pyrene, and benz (a)anthracene). This paper reports findings for the pesticide and $\mathrm{PAH}$ target analytes, which were selected for analysis to provide a regional comparison to previous studies.

Previous studies have detected a variety of contaminants in residential dust, including pesticides and PAH [1-5]. The presence of pesticides in residential dust may result from household pesticide use, pesticide drift, track-in, or the addition of pesticides to home furnishings, such as carpet, during the manufacturing process $[6,7]$. Sources of PAH include track-in soil, indoor combustion sources such as fireplaces, woodstoves, and kerosene heaters, natural or LP gasfired cooking appliances, and smoking [8-10]. Households proximate to roadways with heavy vehicular traffic may also experience high levels of PAH indoors[9]. Residential dust acts as a reservoir for chemical contaminants since they are protected from UV degradation, weathering processes, and microbial action, all of which would normally take place outdoors [2].

Pesticide exposure in children and adults has been associated with a range of symptoms including deficits in neurobehavioral performance [11] and tests of cognitive function [12-14]; delays in psychomotor and mental development [14,15]; and endocrine disruption[5]. Pesticide exposure has also been related to non-Hodgkin's lymphoma [16,17], dementia[14], and Parkinson's disease [18]. Many PAH are known or suspected human and animal mutagens and carcinogens $[9,10]$.

Children may be more highly exposed to contaminants in household dust since behaviorally, children exhibit high levels of handto-mouth activity (including pica) and spend an increased percentage of time near the ground, both of which enhance exposure to dust [19]. Once exposed to environmental hazards, children are much more likely to express toxic effects. Children's developing nervous and immune systems are especially sensitive to allergen and chemical exposure [1] and relative to their smaller size, children's respiratory, absorption, and metabolic rates are higher than adults [19].

*Corresponding author: Marie Lynn Miranda, Ph D, Department of Pediatrics School of Natural Resources and Environment, University of Michigan, 440 Church Street, Ann Arbor, MI 48109, USA, Tel: 734-764-2550; E-mail: mlmirand@umich.edu

Received November 21, 2011; Accepted January 23, 2012; Published January 26, 2012

Citation: Anthopolos R, Keating M, Camann D, Miranda ML (2012) The Occurrence of Pesticides and Polycyclic Aromatic Hydrocarbons in Residential Dust in North Carolina. J Environment Analytic Toxicol 2:122. doi:10.4172/2161-0525.1000122

Copyright: (C) 2012 Anthopolos R, et al. This is an open-access article distributed under the terms of the Creative Commons Attribution License, which permits unrestricted use, distribution, and reproduction in any medium, provided the original author and source are credited. 
Our primary objective was to characterize the occurrence and concentration of pesticides and PAH in household dust in North Carolina. We conducted a screening risk assessment to assess the potential health risk of dust ingestion for those pesticides with oral reference doses developed by the U.S. Environmental Protection Agency (EPA). Since residents are simultaneously exposed to multiple contaminants, we calculated measures of additive risk as well as measures of risk associated with individual contaminants. We also tested the effectiveness of regulatory bans on residential use of certain pesticides as a way to reduce exposure in the indoor environment by examining the frequency of detection and concentration of banned insecticides in homes built prior to and after regulatory bans went into effect.

\section{Materials and Methods}

\section{Participant recruitment}

We recruited study participants via individual appeals mailed to homes, informational posters in public venues, and through community leaders (e.g., pastors and community health directors). We used a Geographic Information System to identify potential residential parcels in Durham, New Hanover, Wayne and Wilson Counties. These counties represent the Piedmont region of North Carolina (Durham County), the coast (New Hanover County), and the largely agricultural coastal plain of eastern North Carolina (Wayne and Wilson Counties). The study was conducted according to a research protocol approved by the Duke University Institutional Review Board.

\section{Questionnaire}

A questionnaire was administered by phone and during an inhome interview. The phone survey collected information about housing characteristics, lead risk factors, allergen/asthma triggers, and combustion risks. During the in-home interview, the indoor environment was assessed in terms of fungal growth, cockroach infestation, rodent infestation, and fire safety. In addition to collecting dust samples, technicians also recorded indoor and outdoor temperatures and relative humidity. Information collected from participants on the year in which the home was built was also incorporated into this analysis.

\section{Dust sample collection}

Composite indoor dust samples were collected between April and October during 2003 and 2004. Trained technicians used a High Volume Small Surface Sampler (HVS-4) (CS3, Sandpoint, ID) attached to a Eureka "9amp The Boss Mighty Might" vacuum to collect a composite dust sample from the living room, near the return vent for the heating, ventilation, and cooling system, near the front and back doors, and in the kitchen. In each house, approximately $10 \mathrm{~mL}$ of dust was collected in a $250 \mathrm{~mL}$ Teflon catch bottle. Samples were stored frozen until they were packaged with dry ice and shipped overnight to Southwest Research Institute (SwRI), San Antonio, Texas for chemical analysis. SwRI stored all samples below $-4^{\circ} \mathrm{C}$ until extraction.

\section{Sample analysis}

Prior to extraction, the entire content of each dust sample bottle was sieved to obtain the fine fraction $(<150 \mathrm{um})$, and split into one 2 $\mathrm{g}$ aliquot (when available), three aliquots of 1 to $2 \mathrm{~g}$ of the two largest dust samples for possible use in matrix spikes, and any remainder as a storage aliquot. One aliquot ( $2 \mathrm{~g}$, if available) of each dust sample was spiked with the appropriate amount (for sample size) of surrogate recovery standard (p-terphenyl-d14, pentachlornitrobenzene, and chlorfenvinphos), Soxhlet-extracted with 6\% diethyl ether in hexanes, and Florisil'-cleaned. Analysis for the 20neutral target analytes was performed using an Agilent 6890 GC equipped with an Agilent 5973 Mass Selective Detector in selected ion monitoring mode (GC/MS/ SIM) to achieve similar detection limits for the targeted pesticides and $\mathrm{PAH}$ as in prior analyses for a study of non-Hodgkin's lymphoma [17]. A DB-5MS 30mx0.25 mm i.d. column (Agilent Technologies, USA) was used for the analysis. Deuterated pesticides and PAH were used as internal standards for quantitation.

We summarized the results of the laboratory analyses of individual dust samples and mailed a reportto each participant. Information about the potential health effects of the environmental contaminants was also included with each report and a toll-free number was provided for the participant to call with any follow-up questions.

\section{Quality control and quality assurance}

In total, 199dust samples were collected and analyzed in eight separate batches. Fifteen field blanks, 23 solvent blanks, and 16 matrix spikes were also analyzed to assess potential sample contamination and method performance. To avoid cross-contamination during sampling, the HVS-4 was disassembled and cleaned using pesticide grade isopropyl alcohol in between samples. None of the 20 pesticide or $\mathrm{PAH}$ analytes were detected in the field and solvent blanks.

The 16 dust matrix spikes indicated that all of the targeted pesticides and PAH were efficiently extracted (70\% to $130 \%)$ from the majority of the nine dusts which were spiked in this study. Most targeted chemicals were uniformly well recovered from these dust matrices. However, carbaryl was poorly recovered $(29 \%-45 \%)$ from three dust matrices. Elevated recoveries $(134 \%$ - 167\%) for methoxychloro, 2,4-D(2ethylhexyl) ester, and 4,4'-DDT were obtained from five dust matrices.

\section{Statistical analysis}

Descriptive statistics were calculated for each of the pesticides and PAH using robust Regression on Order Statistics (ROS). Robust ROS relies on a more limited assumption of normality by which only censored observations follow a specified distribution (usually lognormal in the case of environmental sampling data), which makes the method more robust to skewed distributions than fully parametric approaches [20]. To compute summary statistics, a regression is first fit to detected observations on a probability plot. Second, values for censored observations are predicted from the model based on their normal scores. The predicted values are then combined with detected observations to calculate summary statistics.

The robust ROS method was used for sampled analytes with up to $80 \%$ censored observations [20]. Standard errors for mean and percentile estimates were calculated using a boot strapping technique. For analytes with more than $80 \%$ censored observations, we recorded high percentile and maximum concentrations when observed data was available [20].

For pesticides whose residential use has been restricted or banned, we examined whether the frequency of detection was related to whether the home was constructed before or during the restriction/ban year, or after the restriction/ban year. For accuracy, we cross-referenced participant responses about the year in which the home was built with the year built indicated in publicly-available county tax records. Binary variables based on the restriction/ban year of each pesticide were coded 1 if the home was constructed before or during the restriction/ban year, and if the home was constructed after the restriction/ban year. Pearson's chi-square test was used to detect statistically significant 
differences in the frequency of detection between the pre- and postban/restriction periods

We also examined whether pesticide concentration was related to whether the home was constructed in the pre- or post-restriction/ban period. The generalized Wilcox on test, which accounts for censored data, was used to determine if the median concentration differed significantly by the period in which the sampled residence was built. All statistical analysis was carried out in R 2.80. Statistical significance was defined as $p<0.05$ (two-sided).

\section{Exposure assessment}

We compared our measured data to EPA's chemical-specific oral reference doses (RfD) for those compounds with an RfD published in the Integrated Risk Information System (IRIS) [21]. The RfD (expressed in units of $\mathrm{mg}$ of substance/kg body weight-day) is defined by the EPA as an estimate (with uncertainty spanning perhaps an order of magnitude) of a daily exposure to the human population (including sensitive subgroups) that is likely to be without an appreciable risk of deleterious effects during a lifetime[22].The mean, $90^{\text {th }}$ percentile, and maximum value of each contaminant was used to represent a range of contaminant levels. We used EPA's recommended daily ingestion rates for children aged 1 to $<6$ years of $60 \mathrm{mg} /$ day and $100 \mathrm{mg} /$ day for daily ingestion of dust, and soil and dust, respectively [22]. A daily ingestion rate of $200 \mathrm{mg} /$ day was used to represent the $95^{\text {th }}$ percentile for the daily ingestion rate for a non-pica child [23]. Weight was held constant at $15 \mathrm{~kg}$ which is the rounded average of EPA's recommended weights for children ages 1 to $<6$ years [22].Daily exposure $(\mathrm{mg} / \mathrm{kg}$-day) was calculated by multiplying the concentration of the contaminant (mg/ $\mathrm{kg}$ ) by the daily intake rate ( $\mathrm{mg} /$ day) and dividing by body weight $(\mathrm{kg})$.

A hazard quotient (HQ), a dimensionless ratio of the daily exposure estimate to the $\mathrm{RfD}$, was calculated for each contaminant. A HQ less than 1 is indicative of acceptable risk (for the health endpoint represented by the RfD). Risk of adverse effects is considered elevated as the HQ increases above 1.A hazard index (HI), which is the sum of the HQs, was also calculated. A hazard index provides a measure of additive risk from a mixture of contaminants which have either a similar health effect or affect the same target organ.

\section{Results}

Frequency of detection varied across pesticides and PAH (Table 1). The most frequently detected compounds were PAH. All four PAH were found in at least 97\% (194) of sampled homes; only one home had non-detectable levels of all of the PAH compounds. The frequency of detection across pesticide soften did not coincide with registration status. For example, pesticides with the highest detection rates were currently registered o-phenylphenol and cis- and trans-permethrin, which were found in 95 to $99 \%$ of homes, respectively. However, restricted and banned pesticides were also prevalent: chlorpyrifos, and $\alpha$ - and $\gamma$-chlordane were each detected in more than $60 \%$ of the homes, compared to currently-used 2,4-D(2-ethylhexyl) ester, which was detected in only $2.5 \%$ of homes. The number of different pesticides detected ranged from 2 (occurring in 4 houses) to 13 (occurring in 2 houses). The median number of pesticides in sampled homes was 7 .

A consistent trend emerged in the PAH concentrations found in sampled homes (Table 2). For each estimated percentile, the PAH were in the following order of decreasing concentration: benzo (b) fluoranthene, chrysene/iso-chrysene, benzo (a)pyrene, and benz (a) anthracene. Maximum concentrations were similarly ordered, ranging from $30,500 \mathrm{ng} / \mathrm{g}$ to $47,400 \mathrm{ng} / \mathrm{g}$ for benz (a)anthracene and benzo(b) fluoranthene, respectively.
The registration status of a pesticide often did not inform the concentration level of the pesticide (Table 2). For example, while the two pesticides detected in highest concentration at each estimated percentile and maximum values (cis- and trans-permethrin) are in current use, each of the percentile estimates of banned 4,4'-DDT and $\gamma$-chlordane were greater than those for currently registered carbaryl. In addition, the banned pesticides 4,4'-DDT, and $\alpha$ - and $\gamma$-chlordane each had maximum concentrations and $90^{\text {th }}$ percentile estimates that were higher than those for currently registered o-phenylphenol.

A statistically significant relationship was found between the detection rate for the banned insecticides including 4,4'-DDT, 4,4'DDE, $a$-chlordane, $\gamma$-chlordane, dieldrin, and heptachlor, and whether a home was built before/during, or after the year in which the insecticide was banned (Chi-square test: $\mathrm{P}<0.001$ in all cases except for dieldrin where $\mathrm{P}<0.01$ ) (Table 3 ). Homes built after the ban year had lower detection rates compared to homes built before or during the ban year. This analysis was not carried out on the remaining restricted and banned pesticides because of either low overall detection rates (e.g., alachlor) or too few houses constructed in one of the pre- or postrestriction/ban year periods (e.g., methoxychlor).

Figure 1 shows the distribution of insecticide concentration by whether the sampled home was built before/during or after the ban year for the same six banned insecticides noted above. In each graph, the horizontal line indicates the maximum detection limit for the particular insecticide, whereby values below this limit are interpreted with greater uncertainty than values above this threshold. The highest concentrations of each of these banned insecticides were measured

\begin{tabular}{lll}
\hline & $\%>\mathrm{DL}(\mathrm{n})$ & Range of DL \\
\hline Benz(a)anthracene & $\mathrm{PAH}$ & \\
Benzo(b)fluoranthene & $97.49(194)$ & {$[42,83]$} \\
Benzo(a)pyrene & $99.50(198)$ & $42^{\mathrm{b}}$ \\
Chrysene/iso-chrysene & $97.49(194)$ & {$[42,83]$} \\
& $98.99(197)$ & {$[42,51]$}
\end{tabular}

\begin{tabular}{|c|c|c|}
\hline \multicolumn{3}{|l|}{ Current } \\
\hline 2,4-D(2-ethylhexyl) ester & $2.51(5)$ & {$[14,96]$} \\
\hline Carbaryl & $20.60(41)$ & {$[88,640]$} \\
\hline Cis-permethrin & $98.99(197)$ & {$[43,54]$} \\
\hline Trans-permethrin & $98.49(196)$ & {$[70,100]$} \\
\hline O-phenylphenol & $94.97(190)$ & {$[40,83]$} \\
\hline \multicolumn{3}{|l|}{ Restricted } \\
\hline Alachlor & $1.01(2)$ & {$[14,98]$} \\
\hline Chlorpyrifos & $82.41(164)$ & {$[29,83]$} \\
\hline Diazinon & $32.66(65)$ & {$[14,98]$} \\
\hline Lindane & $4.55(9)$ & {$[29,200]$} \\
\hline \multicolumn{3}{|l|}{ Banned } \\
\hline a-Chlordane & $62.31(124)$ & {$[34,98]$} \\
\hline Y-Chlordane & $70.85(141)$ & {$[34,98]$} \\
\hline $4,4^{\prime}-\mathrm{DDE}$ & $27.64(55)$ & {$[14,83]$} \\
\hline 4,4'-DDT & $38.19(76)$ & {$\left[\begin{array}{ll}43 & 230\end{array}\right]$} \\
\hline Dieldren & $16.58(33)$ & {$[170,490]$} \\
\hline Heptachlor & $36.04(71)$ & {$[34,121]$} \\
\hline Methoxychlor & $26.15(51)$ & {$[68,310]$} \\
\hline
\end{tabular}

aDue to large interference of coeluting compounds, summary statistics for heptachlor, lindane, and methoxychlor account for 197, 198, and 195 households respectively.

${ }^{\mathrm{b} B e n z o}(\mathrm{~b})$ fluoranthene only had one detection limit.

Table 1: Percent detectable concentrations and range of detection limit (DL) for non-detects for each analyte $(\mathrm{N}=199)^{\mathrm{a}}$. 
Citation: Anthopolos R, Keating M, Camann D, Miranda ML (2012) The Occurrence of Pesticides and Polycyclic Aromatic Hydrocarbons in Residential Dust in North Carolina. J Environment Analytic Toxicol 2:122. doi:10.4172/2161-0525.1000122

Page 4 of 8

\begin{tabular}{|c|c|c|c|c|c|c|c|c|}
\hline & \multirow[b]{2}{*}{$\begin{array}{l}\text { Mean } \\
(95 \% \mathrm{Cl})\end{array}$} & \multirow[b]{2}{*}{$\mathrm{Sd}$} & \multirow[b]{2}{*}{$\operatorname{Min}^{\mathrm{b}}$} & \multicolumn{4}{|c|}{ Percentile } & \multirow[b]{2}{*}{$\operatorname{Max}^{b}$} \\
\hline & & & & $25^{\text {th }}$ & $50^{\text {th }}$ & $75^{\text {th }}$ & $90^{\text {th }}$ & \\
\hline \multicolumn{9}{|c|}{$\mathrm{PAH}$} \\
\hline Benz(a)anthracene & $\begin{array}{l}734.20 \\
(510.71,1093.06)\end{array}$ & 2238.72 & $<42$ & $\begin{array}{l}220.00 \\
(194.00,269.00)\end{array}$ & $\begin{array}{l}380.00 \\
(345,426)\end{array}$ & $\begin{array}{l}611.50 \\
(512.5,768)\end{array}$ & $\begin{array}{l}1304.00 \\
(935.94,1702)\end{array}$ & 30500.00 \\
\hline Benzo(b)fluoranthene & $\begin{array}{l}1742.46 \\
(1355.58,2344.70)\end{array}$ & 3593.64 & $<42$ & $\begin{array}{l}607.00 \\
(509.00,737.04)\end{array}$ & $\begin{array}{l}1080.0 \\
(988,1260)\end{array}$ & $\begin{array}{l}1760.0 \\
(1535,1960)\end{array}$ & $\begin{array}{l}3274.0 \\
(2690,3868)\end{array}$ & 47400.00 \\
\hline Benzo(a)pyrene & $\begin{array}{l}956.07 \\
(700.52,1359.54)\end{array}$ & 2514.75 & $<42$ & $\begin{array}{l}303.50 \\
(265.00,367.00)\end{array}$ & $\begin{array}{l}529.00 \\
(480,607)\end{array}$ & $\begin{array}{l}909.50 \\
(795.50,1100.00)\end{array}$ & $\begin{array}{l}1682.00 \\
(1310,2396)\end{array}$ & 34200.00 \\
\hline Chrysene/iso-chrysene & $\begin{array}{l}1392.40 \\
(1065.02,1888.02)\end{array}$ & 3036.93 & $<42$ & $\begin{array}{l}473.00 \\
(413.00,576.54)\end{array}$ & $\begin{array}{l}857.0 \\
(769,960)\end{array}$ & $\begin{array}{l}1370.0 \\
(1170.00,1645.00)\end{array}$ & $\begin{array}{l}2498.0 \\
(1982,3253)\end{array}$ & 40200.00 \\
\hline \multicolumn{9}{|c|}{ Pesticides } \\
\hline \multicolumn{9}{|l|}{ Current } \\
\hline 2,4-D(2-ethylhexyl) ester & - & - & $<14$ & - & - & - & - & 1410 \\
\hline Carbaryl & $\begin{array}{l}1465.62 \\
(517.53,3007.09)\end{array}$ & 9406.48 & $<88$ & $\begin{array}{l}2.02 \\
(0.37,10.03)\end{array}$ & $\begin{array}{l}13.78 \\
(4.21,50.58)\end{array}$ & $\begin{array}{l}120.06 \\
(47.35,292.50)\end{array}$ & $\begin{array}{l}1610.00 \\
(525.80,2894.00)\end{array}$ & 124000 \\
\hline Cis-permethrin & $\begin{array}{l}7565.05 \\
(4938.11,10971.36)\end{array}$ & 21766.53 & $<43$ & $\begin{array}{l}353.50 \\
(285.00,444.00)\end{array}$ & $\begin{array}{l}1070.00 \\
(781,1770)\end{array}$ & $\begin{array}{l}4220.00 \\
(3200.00,6410.00)\end{array}$ & $\begin{array}{l}17180.00 \\
(10168.00,28760.00)\end{array}$ & 218000 \\
\hline Trans-permethrin & $\begin{array}{l}9311.45 \\
(6240.47,13157.74)\end{array}$ & 25200.45 & $<70$ & $\begin{array}{l}536.00 \\
(442.00,795.00)\end{array}$ & $\begin{array}{l}1650.00 \\
(1140,2390)\end{array}$ & $\begin{array}{l}5715.00 \\
(4400.00,8260.00)\end{array}$ & $\begin{array}{l}21360.00 \\
(13500.00,33940.00)\end{array}$ & 234000 \\
\hline O-phenylphenol & $\begin{array}{l}297.62 \\
(203.80,426.48)\end{array}$ & 835.62 & $<40$ & $\begin{array}{l}99.95 \\
(89.60,118.50)\end{array}$ & $\begin{array}{l}166.00 \\
(146.00,183.00)\end{array}$ & $\begin{array}{l}251.50 \\
(212.00,304.00)\end{array}$ & $\begin{array}{l}427.60 \\
(370.00,514.60)\end{array}$ & 8360 \\
\hline \multicolumn{9}{|l|}{ Restricted } \\
\hline Alachlor & - & - & $<14$ & - & - & - & - & 708 \\
\hline Chlorpyrifos & $\begin{array}{l}959.34 \\
(460.29,1661.56)\end{array}$ & 4497.45 & $<29$ & $\begin{array}{l}59.55 \\
(46.70,97.30)\end{array}$ & $\begin{array}{l}181.00 \\
(144.00,246.00)\end{array}$ & $\begin{array}{l}596.00 \\
(438.00,781.50)\end{array}$ & $\begin{array}{l}1320.00 \\
(970.20,1806.00)\end{array}$ & 45600 \\
\hline Diazinon & $\begin{array}{l}75.74 \\
(54.57,102.44)\end{array}$ & 176.20 & $<14$ & $\begin{array}{l}7.93 \\
(4.32,14.52)\end{array}$ & $\begin{array}{l}20.43 \\
(12.95,31.87)\end{array}$ & $\begin{array}{l}61.15 \\
(45.04,103.00)\end{array}$ & $\begin{array}{l}200.40 \\
(143.00,243.00)\end{array}$ & 1860 \\
\hline Lindane & - & - & $<29$ & - & - & - & - & 4970 \\
\hline \multicolumn{9}{|l|}{ Banned } \\
\hline a-Chlordane & $\begin{array}{l}548.78 \\
(390.23,732.86)\end{array}$ & 1247.12 & $<34$ & $\begin{array}{l}29.02 \\
(19.02,43.93)\end{array}$ & $\begin{array}{l}109.00 \\
(69.30,169.00)\end{array}$ & $\begin{array}{l}506.00 \\
(377.00,691.00)\end{array}$ & $\begin{array}{l}1274.00 \\
(985.60,2246.00)\end{array}$ & 12500 \\
\hline Y-Chlordane & $\begin{array}{l}974.09 \\
(692.20,1351.55)\end{array}$ & 2389.32 & $<34$ & $\begin{array}{l}39.92 \\
(28.16,53.60)\end{array}$ & $\begin{array}{l}200.00 \\
(106.00,311.00)\end{array}$ & $\begin{array}{l}984.00 \\
(685.00,1280.00)\end{array}$ & $\begin{array}{l}2464.00 \\
(1598.00,3490.00)\end{array}$ & 25800 \\
\hline 4,4'-DDE & $\begin{array}{l}113.46 \\
(61.95,185.78)\end{array}$ & 461.89 & $<14$ & $\begin{array}{l}2.82 \\
(1.04,7.47)\end{array}$ & $\begin{array}{l}10.43 \\
(5.48,20.42)\end{array}$ & $\begin{array}{l}56.05 \\
(27.87,80.50)\end{array}$ & $\begin{array}{l}181.20 \\
(104.38,314.40)\end{array}$ & 4890 \\
\hline 4,4'-DDT & $\begin{array}{l}1183.60 \\
(462.13,2170.51)\end{array}$ & 6219.59 & $<43$ & $\begin{array}{l}11.28 \\
(4.40,26.02)\end{array}$ & $\begin{array}{l}51.96 \\
(28.69,100.21)\end{array}$ & $\begin{array}{l}341.00 \\
(193.00,534.00)\end{array}$ & $\begin{array}{l}1702.00 \\
(957.81,2724.00)\end{array}$ & 59200 \\
\hline Dieldrin & - & - & $<170$ & - & - & - & $766.00^{c}$ & 6480 \\
\hline Heptachlor & $\begin{array}{l}182.81 \\
(125.97,251.72)\end{array}$ & 453.12 & $<34$ & $\begin{array}{l}9.06 \\
(4.54,17.08)\end{array}$ & $\begin{array}{l}26.04 \\
(16.66,45.65)\end{array}$ & $\begin{array}{l}144.00 \\
(73.80,191.00)\end{array}$ & $\begin{array}{l}515.20 \\
(286.40,800.00)\end{array}$ & 3980 \\
\hline Methoxychlor & $\begin{array}{l}195.07 \\
(117.15,297.10)\end{array}$ & 652.40 & 46.60 & $\begin{array}{l}7.02 \\
(2.32,16.39)\end{array}$ & $\begin{array}{l}21.68 \\
(10.30,41.71)\end{array}$ & $\begin{array}{l}87.80 \\
(49.82,129.00)\end{array}$ & $\begin{array}{l}296.20 \\
(221.00,630.40)\end{array}$ & 5710 \\
\hline
\end{tabular}

aSummary statistics including percentiles, mean and standard deviation were estimated using ROS.

${ }^{\mathrm{b}}$ The minimum and maximum values are based on observed data. Except in the case of methoxychlor, the minimum is a non detect at the minimum detection limit used for a particular compound. For methoxychlor, the minimum is a detected concentration.

${ }^{\mathrm{c}}$ The $95^{\text {th }}$ percentile is reported because the $90^{\text {th }}$ percentile was a censored value.

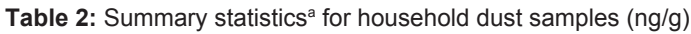

in homes built prior to the respective ban years (as indicated by pre ban year equals 1). Moreover, for each insecticide, in the post ban period, the large part of the concentration distribution was below the maximum detection limit. The General Wilcoxon test revealed statistically significant differences in insecticide concentrations between homes built before/during versus after the ban year $(\mathrm{P}<0.001$ in all cases except for dieldrin where $\mathrm{P}<0.01$ ).

\section{Health risk assessment}

At concentration levels represented by the mean and $90^{\text {th }}$ percentile, HQs for pesticides were one to two orders of magnitude less than 1 when calculated using ingestion rates of $60 \mathrm{mg} / \mathrm{day}, 100 \mathrm{mg} /$ day, and $200 \mathrm{mg} /$ day (Table 4). Registration status of the pesticide did not indicate a consistent relationship with the magnitude of the HQ at these concentration levels. Using maximum concentration values and the highest ingestion rate of $200 \mathrm{mg} /$ day, the only HQs that exceeded 1 were those for the banned insecticides dieldrin and DDT (1.73 and 1.58 , respectively).

Additive risk, as indicated by the HI, exceeded 1 for the pesticide analytes for each ingestion rate when the maximum detected value of each analyte was used. The magnitude of the HI was largely influenced by the maximum values measured for cis-and trans-permethrins, and the banned insecticides $\gamma$-chlordane, DDT, and dieldrin, which together accounted for $90 \%$ of the HI. 
Citation: Anthopolos R, Keating M, Camann D, Miranda ML (2012) The Occurrence of Pesticides and Polycyclic Aromatic Hydrocarbons in Residential Dust in North Carolina. J Environment Analytic Toxicol 2:122. doi:10.4172/2161-0525.1000122

Page 5 of 8

\begin{tabular}{|c|c|c|c|c|c|c|}
\hline & \multirow{2}{*}{$\begin{array}{l}\text { Restriction/ Ban } \\
\text { Year }\end{array}$} & \multicolumn{2}{|c|}{$\begin{array}{l}\text { After the } \\
\text { Restriction/Ban Year }\end{array}$} & \multicolumn{2}{|c|}{ Before/During the Restriction/Ban Year } & \multirow{2}{*}{$\begin{array}{l}\text { Chi-square Test } \\
\text { Frequency of detection between } \\
\text { Restriction/Ban Periods }\end{array}$} \\
\hline & & No. of Houses & \% Detects (No.) & No. of Houses & \% Detects (No.) & \\
\hline \multicolumn{7}{|c|}{ Restricted } \\
\hline Alachlor & 1988 & 43 & $2.33(1)$ & 147 & $0.68(1)$ & - \\
\hline Chlorpyrifos & 2001 & 2 & $50.00(1)$ & 188 & $83.51(157)$ & - \\
\hline Diazinon & 2002 & 1 & 0 & 189 & $33.86(64)$ & - \\
\hline Lindane & $1977^{b}$ & 64 & 0 & 126 & $7.14(9)$ & - \\
\hline \multicolumn{7}{|l|}{ Banned } \\
\hline a-Chlordane & 1988 & 43 & $16.28(7)$ & 147 & $78.23(115)$ & $P<0.001$ \\
\hline Y-Chlordane & 1988 & 43 & $30.23(13)$ & 147 & $85.03(125)$ & $P<0.001$ \\
\hline 4,4'-DDE & 1972 & 70 & $8.57(6)$ & 120 & $40.83(49)$ & $P<0.001$ \\
\hline 4,4'-DDT & 1972 & 70 & $15.71(11)$ & 120 & $54.17(65)$ & $P<0.001$ \\
\hline Dieldrin & 1987 & 45 & $2.22(1)$ & 145 & $22.07(32)$ & $P<0.01$ \\
\hline Heptachlor & 1988 & 42 & $2.34(1)$ & 146 & $46.26(68)$ & $P<0.001$ \\
\hline Methoxychlor & 2000 & 4 & 0 & 182 & $26.37(48)$ & - \\
\hline
\end{tabular}

aNine homes had missing values for the year in which the house was constructed.

${ }^{\mathrm{b}}$ The noted year is when indoor fumigation was cancelled. Lindane is still in use for lice treatment.

Table 3: Percent detectable concentrations for restricted or banned pesticides by whether the sampled home was built before/during or after the restriction or ban year $\left(\mathrm{N}=190^{\mathrm{a}}\right)$.
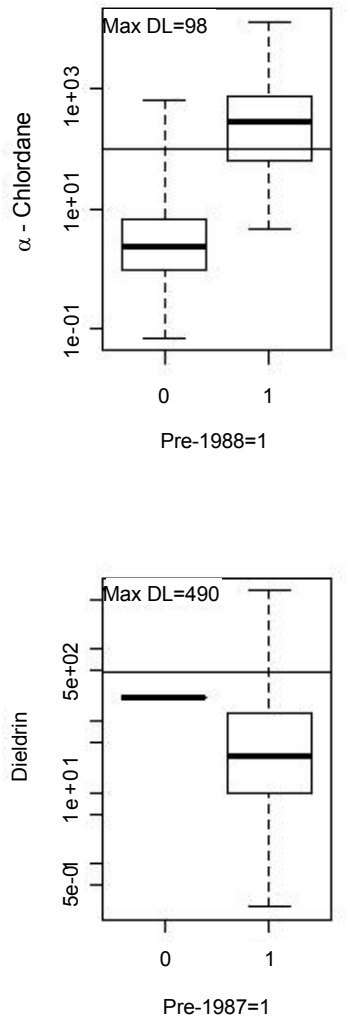
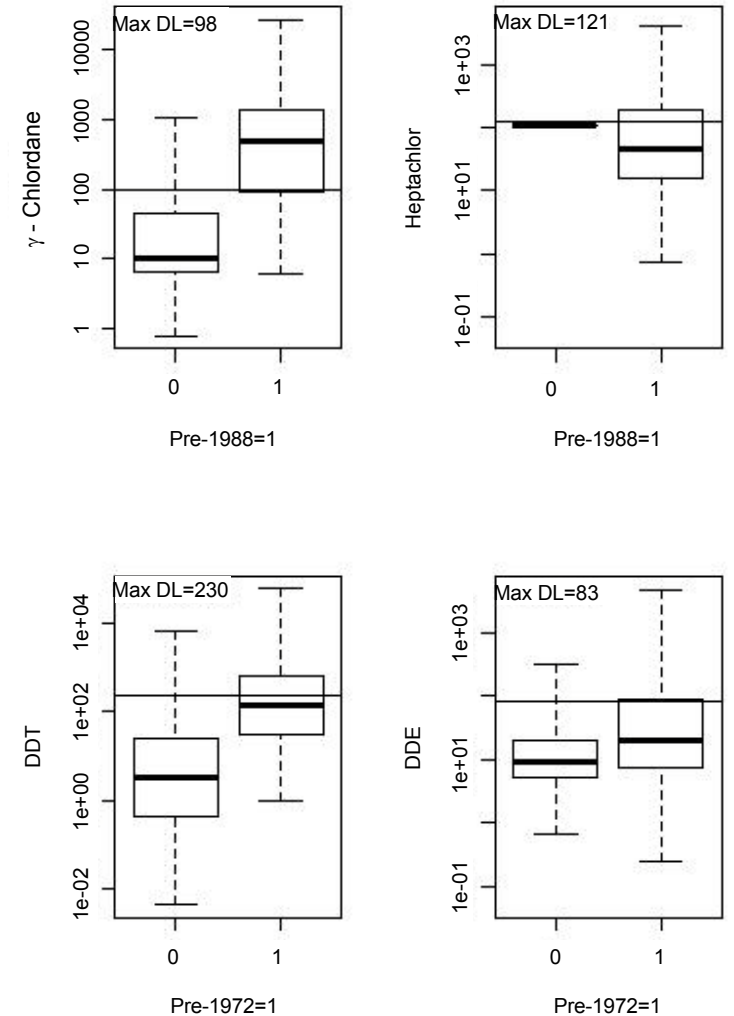

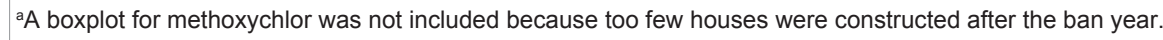

Figure 1: Box plots of banned insecticide concentrations ${ }^{\mathrm{a}}(\mathrm{ng} / \mathrm{g})$ by whether the sampled home was built before/during or after the ban year. Horizontal line represents the maximum detection limit $(\mathrm{N}=190)$.

\section{Discussion}

Compared to other U.S. based studies, the median and mean values for the PAH benz(a)anthracene and benzo(a)pyrene that we measured in North Carolina were higher than those measured by others in North Carolina [9,24-26], Texas [27], and Iowa, Michigan, California, and Washington [28]. (Please refer to Supplemental Materials table 1 for a detailed study comparison.) In addition, our median North Carolina values were higher than similar studies in Germany [29-31], Australia [32], Italy [33], and Denmark [34]. Higher median values than those we report for benz(a)anthracene and benzo(a)pyrene were measured in Cape Cod, MA [5] and in Ohio homes [26].Season of sampling might affect the percentile differences across regions. If this is the case, then our summer sampling season would compare most closely with the 


\begin{tabular}{|c|c|c|c|c|c|c|c|c|c|}
\hline \multirow{2}{*}{$\begin{array}{r}\text { Ingestion Rate: } \\
\text { Contaminant Level: }\end{array}$} & \multicolumn{3}{|c|}{60 mg/Day } & \multicolumn{3}{|c|}{100 mg/day } & \multicolumn{3}{|c|}{$200 \mathrm{mg} /$ day } \\
\hline & Mean & 90th & Max & Mean & 90th & Max & Mean & 90th & Max \\
\hline \multicolumn{10}{|c|}{ Pesticides Hazard Quotients } \\
\hline \multicolumn{10}{|l|}{ Current Use } \\
\hline $2,4-D$ & na & na & na & na & na & 0.00 & na & na & 0.00 \\
\hline Carbaryl & $<0.01$ & $<0.01$ & $<0.01$ & $<0.01$ & $<0.01$ & 0.01 & $<0.01$ & $<0.01$ & 0.02 \\
\hline Cis permethrin & $<0.01$ & $<0.01$ & 0.02 & $<0.01$ & $<0.01$ & 0.03 & $<0.01$ & $<0.01$ & 0.06 \\
\hline Trans permethrin & $<0.01$ & $<0.01$ & 0.02 & $<0.01$ & $<0.01$ & 0.03 & $<0.01$ & 0.01 & 0.06 \\
\hline \multicolumn{10}{|l|}{ Restricted } \\
\hline Alachlor & $<0.01$ & $<0.01$ & na & $<0.01$ & $<0.01$ & $<0.01$ & $<0.01$ & $<0.01$ & 0.00 \\
\hline Chlorpyrifos & $<0.01$ & $<0.01$ & 0.06 & $<0.01$ & $<0.01$ & 0.10 & $<0.01$ & 0.01 & 0.20 \\
\hline \multicolumn{10}{|l|}{ Banned } \\
\hline Alpha chlordane & $<0.01$ & 0.01 & 0.10 & 0.01 & 0.02 & 0.17 & 0.01 & 0.03 & 0.33 \\
\hline Gamma chlordane & 0.01 & 0.02 & 0.21 & 0.02 & 0.03 & 0.34 & 0.03 & 0.07 & 0.69 \\
\hline DDT & 0.01 & 0.01 & 0.47 & 0.01 & 0.02 & 0.79 & $<0.01$ & 0.05 & 1.58 \\
\hline Dieldrin & $<0.01$ & 0.06 & 0.52 & 0.06 & 0.10 & 0.86 & $<0.01$ & 0.20 & 1.73 \\
\hline Heptachlor & $<0.01$ & $<0.01$ & 0.03 & $<0.01$ & 0.01 & 0.05 & $<0.01$ & 0.01 & 0.11 \\
\hline Methoxychlor & $<0.01$ & $<0.01$ & $<0.01$ & $<0.01$ & $<0.01$ & 0.01 & $<0.01$ & $<0.01$ & 0.02 \\
\hline Total Pesticides Hazard Index & 0.02 & 0.10 & 1.43 & 0.10 & 0.18 & 2.40 & 0.04 & 0.37 & 4.79 \\
\hline
\end{tabular}

Table 4: Hazard quotients and hazard indices for pesticides using three ingestion rates and analyte concentrations.

Cape Cod study [5], which also took place during the summer. Rudel et al. report additional data for benz(a)anthracene and benzo(a)pyrene from 119 homes on Cape Cod [5]. The frequencies of detection for the two PAH were lower on Cape Cod (76\% and 95\%, respectively, compared to $98 \%$ in North Carolina); however, median values were similar, and maximum values were about an order of magnitude higher on Cape Cod than in North Carolina [5]. Sources of PAH that have been associated with PAH in residential dust are vehicular traffic, fires, power plants, smoking, cooking, residential heating sources, and house characteristics $[10,26,35]$. A contributing factor to the higher $\mathrm{PAH}$ levels in Cape Cod and Ohio homes may be the colder climate and the use of oil, natural gas, and/or LP gas for home heating. For example, more than $80 \%$ of households in Ohio and Massachusetts use natural gas, fuel oil, or LP gas for home heating. By comparison, only $49 \%$ of North Carolina homes use these types of furnaces for residential heating [36]. Other sources of PAH, including cigarette/tobacco smoke and wood burning home heating appliances, however, are common in the southeastern U.S., likely giving rise to the nearly ubiquitous presence of these environmental contaminants in sampled homes.

Benzo(b)fluoranthene and chrysene/iso-chrysene levels were also among the highest of the research articles that we reviewed. Only Morgan et al.'s study in Ohio reported higher benzo(b)fluoranthene mean and median levels than those found in our study [26]. This study also reported higher mean chrysene/iso-chrysene levels than those found in our study- note that our median value was higher [26].

For pesticides, neither the frequency of detection nor the concentration of a given pesticide was related to whether the pesticide was currently registered, restricted, or banned. Both detection frequency and concentration seem to be influenced by end use (e.g., household use of chlorpyrifos versus commercial agriculture application of alachlor) and persistence in the environment (e.g., the long-lived organochlorines compared to the more easily degraded permethrinbased pesticides). These factors may explain our findings that currently registered pesticides in common household use were frequently detected (e.g., o-phenylphenol and cis- and trans-permethrin, which were found in 95 to $99 \%$ of homes, respectively), as were restricted organophosphates and banned organochlorines (e.g., chlorpyrifos and $\alpha$ - and $\gamma$-chlordane, which were detected in more than $60 \%$ of the homes). In contrast, 2,4-D(2-ethylhexyl) ester (currently registered), alachlor and lindane (restricted), whose primary applications are in commercial agriculture, were detected in only 5,2 , and 9 of the tested homes, respectively. The lack of agricultural pesticides in the homes we sampled was not unexpected since the majority of our homes were located in urban areas with few participants employed in agriculture.

Our results also confirm prior research that the concentration of pesticides inside the home declines following regulatory bans on residential use [37]. However, even a house built after a pesticide was banned may still have measurable levels of a banned compound in household dust, indicating that homeowners may have continued to use banned products that were previously purchased, that the pesticides remained on store shelves for some time after the ban, or that pesticides were tracked in from outside. Our results offer insight into the role of regulatory bans as a means to reduce residential exposure and may have implications for regulatory reform of the Toxic Substances Control Act in the U.S., the primary legislation for regulating uses of current and emerging industrial chemicals.

The pesticides we measured in this study can be compared to similar studies in the U.S. $[1,4,5,38]$ (For details, please refer to the literature summary tables in the Supplemental Materials section.). We limit this comparison to studies in the U.S., since pesticides are subject to different regulatory requirements in different countries. In addition, since different studies have sampled household dust in different years, and have used a variety of imputation methods to handle values below the analytical detection limit, an absolute comparison between measured concentrations cannot be made. In general, North Carolina homes seem to have similar levels of current use and restricted use pesticides as other regions of the country. In contrast, concentrations of certain banned insecticides ( $\alpha$ - and $\gamma$-chlordane, DDE, and DDT) appear higher in North Carolina than other regions of the U.S., perhaps due to the greater prevalence of mosquitos and termites and the previous common practice of routine spraying of these insecticides for pest control.

Potential health effects from the mixture of contaminants measured in the residential house dust in this study will depend on the concentration of the contaminants in the dust, the amount of dust ingested or inhaled in a day, the length of the exposure period, and the age of the individual at the time of exposure. Our risk assessment 
resulted in an HQ for individual pesticides of $<1$ under almost all exposure scenarios. This finding indicates that the potential health risk for a child ingesting pesticide residues in dust at these concentrations would be considered acceptable by the EPA. Exceptions are for DDT and dieldrin at the maximum value and $200 \mathrm{mg} /$ day ingestion rate. Since the maximum values for DDT and dieldrin are 35 and 8 times higher, respectively, than the $90^{\text {th }}$ percentile values for these pesticides, the potential for this exposure scenario in most households would probably be low, especially since dieldrin and DDT were detected in only 17 and 39 percent of tested homes, respectively. Of the remaining pesticides, under each ingestion rate scenario using the maximum value, $\gamma$-chlordane had an HQ at least two times higher than other pesticides, but still $<1$ in all cases.

The cumulative $\mathrm{HI}$ for pesticides were $>1$ under all ingestion rate scenarios when calculated using the maximum value HQs. DDT and dieldrin together accounted for about $70 \%$ of the $\mathrm{HI}$, as a result of the higher individual HQs for these 2 contaminants, and $\gamma$-chlordane contributed about $14 \%$ to the total HI. Using the mean or $90^{\text {th }}$ percentile values did not result in HIs $>1$ under any of the ingestion rate scenarios which indicates that for the majority of homes tested, the mixture of pesticides found in dust would not be expected to pose a health risk. However, individual households may have much higher exposure than the majority of the population since, similar to the findings of Rudel et al., the maximum concentration of every pesticide exceeded the $90^{\text {th }}$ percentile concentration by at least 10 -fold or more[5].

A key limitation of our screening risk assessment is that oral RfDs are lacking for many of the analytes (e.g., the PAH), so we could not include all contaminants in the cumulative assessment. In addition, the RfDs that are available are based on single health endpoints, most related to hepatic effects. A single-endpoint RfD does not take into account other potential health impacts such as endocrine disruption, or additive or synergistic effects from concurrent exposure to multiple contaminants. We also focused on non-cancer effects; Maertens et al. reported on the mutagenic hazards of PAH in household dust, an endpoint which could be incorporated into future work [10]. We did not measure air concentrations inside the homes; however, inhalation and dermal penetration would also be expected to contribute to overall exposure to these semi volatile chemicals $[5,37,39]$.

\section{Conclusions}

Household dust in North Carolina homes serves as a reservoir for a variety of pesticides and PAH. Contamination with legacy pollutants, as well as emerging contaminants, indicates chronic low level exposure in most households. The potential health risks from ingestion of household dust appear to be in the acceptable range of risk for the majority of households when compared to EPA's current reference doses. However, more conservative exposure scenarios (i.e., higher ingestion rates combined with higher concentrations) raise potential health concerns for some pesticides for households in which maximum concentrations were measured.

Research areas include a need for the re-evaluation of existing reference doses to incorporate new data on additional known health impacts such as non-Hodgkin's lymphoma [16,17], endocrine disruption [5], low birth weight [40], and behavioral disorders in children exposed to residential pesticides in utero [15]. There is also a need to develop reference doses for additional pollutants, such as the $\mathrm{PAH}$, and to consider the potential health impacts of chronic low-level exposure to mixtures of banned and current use pesticides that are consistently found in households across North Carolina and nationally.
In addition to alerting consumers about safe handling, use, and storage of current use pesticides, particularly in households with children, there is a need to raise awareness about legacy contamination from banned pesticides. Education and outreach efforts could be targeted towards residents living in housing built prior to the year that organo chlorine compounds were banned for residential uses.

\section{Acknowledgements}

This work has been supported by the U.S. Department of Housing and Urban Development, the Robert Wood Johnson Foundation, and the Wallace Genetic Foundation. The authors would like to thank Michelle Abrams, Jeffrey Davis, M. Alicia Overstreet Galeano, Matthew Stiegel, Wayne Thomann, and Carolina Pungiluppi-Tono for their contributions to collecting the environmental samples and building the database that underlies this analysis.

\section{References}

1. Colt JS, Lubin J, Camann D, Davis S, Cerhan J, et al (2004) Comparison of pesticide levels in carpet dust and self-reported pest treatment practices in four US sites. J Expo Anal Environ Epidemiol 14: 74-83.

2. Lewis RG, Fortmann RC, Camann DE (1994) Evaluation of methods for monitoring the potential exposure of small children to pesticides in the residential environment. Arch Environ Contam Toxicol 26: 37-46.

3. Ward MH, Colt JS, Metayer C, Gunier RB, Lubin J, et al. (2009) Residentia exposure to polychlorinated biphenyls and organochlorine pesticides and risk of childhood leukemia. Environ Health Perspect 117: 1007-1013.

4. Hwang HM, Park EK, Young TM, Hammock BD (2008) Occurrence of endocrine-disrupting chemicals in indoor dust. Sci Total Environ 404: 26-35.

5. Rudel RA, Camann DE, Spengler JD, Korn LR, Brody JG (2003) Phthalates, alkylphenols, pesticides, polybrominated diphenyl ethers, and other endocrinedisrupting compounds in indoor air and dust. Environ Sci Technol 37: 45434553.

6. Butte W (2004) Sources and Impacts of Pesticides in Indoor Environments. The Handbook of Environmental Chemistry 4: 89-116.

7. Bradman MA, Harnly ME, Draper W, Seidel S, Teran S, et al. (1997) Pesticide exposures to children from California's Central Valley: results of a pilot study. $J$ Expo Anal Environ Epidemiol 7: 217-234.

8. Lewis RG, Fortune CR, Willis RD, Camann DE, Antley JT (1999) Distribution of pesticides and polycyclic aromatic hydrocarbons in house dust as a function of particle size. Environ Health Perspect 107: 721-726.

9. Chuang JC, Callahan PJ, Lyu CW, Wilson NK (1999) Polycyclic aromatic hydrocarbon exposures of children in low-income families. J Expo Anal Environ Epidemiol 9: 85-98.

10. Maertens RM, Bailey J, White PA (2004) The mutagenic hazards of settled house dust: a review. Mutat Res 567: 401-425.

11. Keifer MC, Mahurin RK (1997) Chronic Neurologic Effects of Pesticide Overexposure. Occup Med 12: 291-304

12. Wesseling C, Keifer M, Ahlbom A, McConnell R, Moon JD, et al. (2002) Longterm Neurobehavioral Effects of Mild Poisonings with Organophosphate and n-Methyl Carbamate Pesticides among Banana Workers. Int J Occup Environ Health 8: 27-34.

13. Savage EP, Keefe TJ, Mounce LM, Heaton RK, Lewis JA, et al. (1988) Chronic Neurological Sequelae of Acute Organophosphate Pesticide Poisoning. Arch Environ Health 43: 38-45.

14. Kamel F, Hoppin JA (2004) Association of pesticide exposure with neurologic dysfunction and disease. Environ Health Perspect 112: 950-958.

15. Rauh VA, Garfinkel R, Perera FP, Andrews HF, Hoepner LA, et al. (2006) Impact of Prenatal Chlorpyrifos Exposure on Neurodevelopment in the First 3 Years of Life Among Inner-City Children. Pediatrics 118: e1845-e1859.

16. Colt JS, Davis S, Severson RK, Lynch CF, Cozen W, et al. (2006) Residential Insecticide Use and Risk of Non-Hodgkin's Lymphoma. Cancer Epidemiol Biomarkers Prev 15: 251-257.

17. Colt JS, Severson RK, Lubin J, Rothman N, Camann D, et al. (2005) Organ chlorines in carpet dust and non-Hodgkin lymphoma. Epidemiology 16: 516525. 
Citation: Anthopolos R, Keating M, Camann D, Miranda ML (2012) The Occurrence of Pesticides and Polycyclic Aromatic Hydrocarbons in Residential Dust in North Carolina. J Environment Analytic Toxicol 2:122. doi:10.4172/2161-0525.1000122

18. Le Couteur DG, McLean AJ, Taylor MC, Woodham BL, Board PG (1999) Pesticides and Parkinson's Disease. Biomed Pharmacother 53: 122-130.

19. Etzel R (1999) Handbook of Pediatric Environmental Health. American Academy of Pediatrics, Elk Grove Village.

20. Helsel DR (2005) Computing Summary Statistics. Nondetects and Data Analysis: Statistics for Censored Environmental Data. John Wiley \& Sons, Hoboken, NJ.

21. US Environmental Protection Agency (2011) Integrated Risk Information System (IRIS).

22. U.S.Environmental Protection Agency (2008) Body Weight. U S EPA ChildSpecific Exposure Factors Handbook.

23. Stanek EJ III, Calabrese EJ (1995) Daily estimates of soil ingestion in children. Environ Health Perspect 103: 276-285.

24. Wilson NK, Chuang JC, Lyu C (2001) Levels of persistent organic pollutants in several child day care centers. J Expo Anal Environ Epidemiol 11: 449-458.

25. Wilson NK, Chuang JC, Lyu C, Menton R, Morgan MK (2003) Aggregate exposures of nine preschool children to persistent organic pollutants at day care and at home. J Expo Anal Environ Epidemiol 13: 187-202.

26. Morgan MK, Sheldon LS, Croghan CW, Chuang JC, Lordo RA, et al. (2004) A Pilot Study of Children's Total Exposure to Persistent Pesticides and Other Persistent Organic Pollutants (CTEPP). EPA/600/R-041/193.

27. Mukerjee S, Ellenson WD, Lewis RG, Stevens RK, Somerville MC, et al. (1997) An environmental scoping study in the Lower Rio Grande Valley of Texas -3. Residential microenvironmental monitoring for air, house dust, and soil. Environment International 23: 657-673.

28. Camann DE, Colt JS, Zuniga MM (2002) Distributions and quality of pesticide, PAH, and PCB measurements in bag dust from four areas of USA. Indoor Air 2002: $860-864$

29. Fromme H, Lahrz T, Piloty M, Gebhardt H, Oddoy A, et al. (2004) Polycyclic aromatic hydrocarbons inside and outside of apartments in an urban area. Sci Total Environ 326: 143-149.
30. Hansen D, Krause G, Volland G, Zoltzer D, Jovanovic S, et al. (2001) Wohnungen mit teerhaltigen Parkettklebern. Gefahrstoffe-Reinhalt Luft 61: 2-7.

31. Pohner A, Simrock S, Thumulla J, Weber S, Wirkner T (1997) Hintergrundbelastung des Hausstaubes von Privathaushalten mit mittel- und schwerfluchtigen organischen Schadstoffen.

32. Robertson ST, Ayoko GA, Duigu JR (2005) Elemental and Polycyclic Aromatic Hydrocarbon Compositions of House Dust in Brisbane, Australia. Proceedings, Indoor Air 2005 II: 1536-1540.

33. Mannino MR, Orecchio S (2008) Polycyclic aromatic hydrocarbons (PAHs) in indoor dust matter of Palermo (Italy) area: Extraction, GC-MS analysis, distribution and sources. Atmos Environ 42: 1801-1817.

34. Langer S, Weschler CJ, Fischer A, Beko G, Toftum J, et al. (2010) Phthalate and $\mathrm{PAH}$ concentrations in dust collected from Danish homes and daycare centers. Atmos Environ 44: 2294-2301.

35. Whitehead T, Metayer C, Gunier RB, Ward MH, Nishioka MG, et al. (2011) Determinants of polycyclic aromatic hydrocarbon levels in house dust. J Expo Sci Environ Epidemiol 21: 123-132.

36. US Energy Information Administration (2011) Independent Statistics and Analysis.

37. Whyatt RM, Garfinkel R, Hoepner LA, Holmes D, Borjas M, et al. (2007) Within- and Between-Home Variability in Indoor-Air Insecticide Levels during Pregnancy among an Inner-City Cohort from New York City. Environ Health Perspect 115: 383-389.

38. Morgan MK, Sheldon LS, Croghan CW, Jones PA, Chuang JC, et al. (2007) An observational study of 127 preschool children at their homes and daycare centers in Ohio: environmental pathways to cis- and trans-permethrin exposure. Environ Res 104: 266-274.

39. Whitmore RW, Immerman FW, Camann DE, Bond AE, Lewis RG, et al. (1994) Non-occupational exposures to pesticides for residents of two U.S. cities. Arch Environ Contam Toxicol 26: 47-59.

40. Whyatt RM, Rauh V, Barr DB, Camann DE, Andrews HF, et al. (2004) Prenata insecticide exposures and birth weight and length among an urban minority cohort. Environ Health Perspect 112: 1125-1132. 